\title{
Axon Withdrawal during Synapse Elimination at the Neuromuscular Junction Is Accompanied by Disassembly of the Postsynaptic Specialization and Withdrawal of Schwann Cell Processes
}

\author{
Susan M. Culican, Carla C. Nelson, and Jeff W. Lichtman \\ Department of Anatomy and Neurobiology, Washington University School of Medicine, St Louis, MO 63110
}

Nerve terminal withdrawal is accompanied by a loss of acetylcholine receptors (AChRs) at corresponding postsynaptic sites during the process of synapse elimination at developing (Balice-Gordon and Lichtman, 1993) and reinnervated adult (Rich and Lichtman, 1989a) neuromuscular junctions. Aside from AChR and nerve terminal loss, however, the molecular and cellular alterations that occur at sites of elimination are unknown. To gain a better understanding of the cascade of events that leads to the disassembly of synaptic sites during the synapse elimination process, we surveyed the distribution of molecular elements of the postsynaptic specialization, the basal lamina, and supporting Schwann cells during the process of synapse elimination that occurs after reinnervation. In addition, quantitative techniques were used to determine the temporal order of disappearance of molecules that were lost relative to the loss of postsynaptic AChRs. We found that the

Synapse elimination is a term used to describe naturally occurring retraction of functional inputs in many parts of the developing nervous system (Lichtman, 1995). Synapse elimination is also recapitulated in adult animals after nerve regeneration (MacArdle, 1975; Lichtman, 1980; Rich and Lichtman, 1989a). Despite its ubiquity, the underlying mechanisms are incompletely understood. Because of its accessibility and simplicity, the neuromuscular junction is an ideal site to study the mechanism of synapse elimination. In mammals, each neuromuscular junction undergoes a transition from multiple to single innervation, typically during the first few weeks of postnatal life (Redfern, 1970; Brown et al., 1976) and, in adults, within several weeks of nerve return after nerve crush (Rich and Lichtman, 1989a).

In vivo monitoring of individual neuromuscular junctions undergoing synapse loss has shown that axon retraction is accompanied by at least one change in the postsynaptic apparatus: a disappearance of acetylcholine receptors (AChRs) (Rich and Lichtman, 1989a; Balice-Gordon and Lichtman, 1993). This postsynaptic change occurs early in the process, because AChR loss begins before the complete retraction of presynaptic inputs. Physiological evidence suggests that the nerve terminal overlying regions in which receptor density is falling is not only present but

\footnotetext{
Received Jan. 15, 1998; revised April 15, 1998; accepted April 17, 1998.

This work was supported by National Institutes of Health and the Muscular Dystrophy Association.

We thank Drs. Jonathan B. Cohen and Joshua R. Sanes for their generous gifts of antibodies and helpful discussions of this work.

Correspondence should be addressed to Dr. Jeff W. Lichtman, Department of Anatomy and Neurobiology, Box 8108, Washington University School of Medicine, 660 South Euclid Avenue, St. Louis, MO 63110.

Copyright (C) 1998 Society for Neuroscience $\quad 0270-6474 / 98 / 184953-13 \$ 05.00 / 0$
}

dismantling of the postsynaptic specialization was inhomogeneous, with evidence of rapid dissolution of some aspects of the postsynaptic apparatus and slower loss of others. We also observed a loss of Schwann cell processes from sites of synapse elimination, with a time course similar to that seen for nerve terminal retraction. In contrast, all of the extracellular markers that we examined were lost slowly from sites of synapse loss. We therefore conclude that the synapse elimination process is synapse-wide, removing not only nerve terminals but also Schwann cells and many aspects of the postsynaptic apparatus. The disassembly occurs in a stereotyped sequence with some synaptic elements appearing much more stable than others.

Key words: neuromuscular junction; synapse elimination; AChR; postsynaptic specialization; Schwann cell; synaptic competition temporarily still releasing transmitter (Colman et al., 1997), suggesting that the postsynaptic receptor loss begins before presynaptic function ceases. Because the postsynaptic changes begin so early in the synapse elimination process, it is possible that the postsynaptic cell is an intermediary in the competition between converging inputs. Experiments using focal blockade of AChRs to manipulate activity patterns within a single junction support the hypothesis that the postsynaptic cell is the intermediary and argue that changes in the postsynaptic cell may instigate nerve terminal removal (Balice-Gordon and Lichtman, 1994).

With the exception of AChRs and nerve terminal loss, the only other molecule that has been studied during synapse elimination is acetylcholinesterase ( $\mathrm{AChE})$, which is maintained at reinnervated junctional sites long after synapse elimination has removed nerve terminals and AChRs (Rich and Lichtman, 1989a). This study examines what kinds of alterations occur in the postsynaptic cell during synapse elimination. In particular, we wanted to find out whether the changes that occur in AChR distribution during synapse elimination are limited to that molecule or represent part of a more general dismantling of the synaptic apparatus. In addition, we have surveyed several extracellular markers of the synaptic site and Schwann cells. Our results show that many synaptic elements are lost during the synapse elimination process, but that they disappear from synaptic sites at different times.

\section{MATERIALS AND METHODS}

Denervation of the sternomastoid muscle. Seven- to 10-week-old female mice (20-30 gm, CF1/B strain; Harlan Sprague Dawley, Indianapolis, IN) or $100 \mathrm{gm}$ female rats (HSD, Harlan Sprague Dawley) were anesthetized with an intraperitoneal injection ( $5 \mu \mathrm{l} / \mathrm{gm}$ body weight) of ketamine (347.8 mg; Aveco, Fort Dodge, IA) and xylazine $(52.2 \mathrm{mg}$, 


\begin{tabular}{|c|c|c|c|c|}
\hline Marker & Concentration & Type & Reference & Source \\
\hline \multicolumn{5}{|l|}{ Postsynaptic } \\
\hline Rapsyn (43k) & $1: 200$ & $\begin{array}{l}\text { mAb194Fa; mouse monoclonal. Column- } \\
\text { purified hybridoma supernatant }\end{array}$ & Carr et al., 1989 & J. B. Cohen \\
\hline Phosphotyrosine & $1: 200$ & mAb4G10; mouse monoclonal & Qu et al., 1990 & Upstate Biochem. Inc. \\
\hline Epsilon subunit & $1: 300$ & $\begin{array}{l}\text { Peptide purified rabbit polyclonal anti- } \\
\text { serum }\end{array}$ & Gu and Hall, 1988 & Peptide purified polyclonal \\
\hline $\begin{array}{l}\text { Utrophin (dystrophin-related } \\
\text { peptide) }\end{array}$ & $1: 100$ & $\begin{array}{l}\text { mAb12B6; mouse monoclonal specific } \\
\text { for Utrophin }\end{array}$ & Ohlendieck et al., 1991 & Novacastra Labs \\
\hline Syntrophin (58k) & $1: 200$ & $\begin{array}{l}\text { mAb20G4; column-purified hybridoma } \\
\text { supernatant }\end{array}$ & Carr et al., 1989 & JB Cohen \\
\hline Dystrophin & $1: 300$ & $\begin{array}{l}\text { mAb1808; mouse monoclonal specific for } \\
\text { dystrophin }\end{array}$ & Sealock et al., 1991 & Boehringer Mannheim \\
\hline \multicolumn{5}{|l|}{ Extracellular } \\
\hline Laminin $\beta 2$ & $1: 1000$ & mAbD5; mouse monoclonal & Hunter et al., 1989b & J. R. Sanes \\
\hline Laminin $\alpha 5$ & $1: 300$ & Rabbit polyclonal antiserum & Miner et al., 1995 & J. R. Sanes \\
\hline NCAM & $1: 500$ & Rabbit polyclonal antiserum & Covault and Sanes, 1986 & J. R. Sanes \\
\hline \multicolumn{5}{|l|}{ Supporting cells } \\
\hline Schwann Cell, S-100 protein & 1: 1000 & $\begin{array}{l}\text { Rabbit polyclonal purified by affinity } \\
\text { chromatography }\end{array}$ & $\begin{array}{l}\text { Woolf et al., 1992. Son and } \\
\text { Thompson, 1995a,b }\end{array}$ & Dako \\
\hline \multicolumn{5}{|l|}{ Secondary Abs } \\
\hline CY3 conjugates & $\begin{array}{l}1: 1500 \\
1: 1000\end{array}$ & $\begin{array}{l}\text { Donkey anti-rabbit } \\
\text { Goat anti-mouse }\end{array}$ & & Jackson Research Labs \\
\hline FITC conjugates & $\begin{array}{l}1: 200 \\
1: 200 \\
1: 200\end{array}$ & $\begin{array}{l}\text { Donkey anti-rabbit } \\
\text { Goat anti-rabbit } \\
\text { Goat anti-mouse }\end{array}$ & & $\begin{array}{l}\text { Jackson Research Labs } \\
\text { Cappel } \\
\text { Cappel }\end{array}$ \\
\hline
\end{tabular}

*Labeled rat but not mouse tissue.

Lloyd Laboratories) in $20 \mathrm{ml}$ of $0.9 \% \mathrm{NaCl}$. The sternomastoid muscle and its nerve supply were exposed, and denervations were performed as described previously (Rich and Lichtman, 1989a). Briefly, under aseptic conditions, a midline incision was made in the neck, and the salivary glands were retracted to expose the sternomastoid muscle. The nerve to the sternomastoid was lesioned at its medial aspect in one of two ways. For permanent denervation a 2- to 3-mm-long segment of nerve was cut out and removed. For transient denervation to induce multiple innervation we performed a "double nerve crush," in which the nerve was crushed with forceps two times, $4 \mathrm{~d}$ apart (in mice) or $5 \mathrm{~d}$ apart (in rats). After nerve cut or crush, the wound was closed, and the animal was allowed to recover.

Because of variability in the timing of reinnervation of muscle fibers within a muscle, it is not possible to precisely define the beginning of the synapse elimination process at any one junction based on the time after nerve crush. Therefore, we studied junctions that had stereotyped characteristics of remodeling [Vicia Villosa Lectin (VVA) staining at sites that lack AChRs and faint AChR staining; see Results] during a window of time when multiple innervation is being removed from the muscle as a whole.

Lipophilic dye labeling of sternomastoid muscle. $\mathrm{DiIC}_{22}$ (3) (DiI) and 4-Di-16-Asp (DiA) (Molecular Probes, Eugene, OR) labeling of axons in the nerve to the sternomastoid muscle has been described previously (Balice-Gordon et al., 1993). In short, animals $(n=6)$ were killed 12-16 $\mathrm{d}$ after the second of two nerve crushes. For each muscle, the nerve was split into two branches, and each branch was carefully placed into crystals of DiI or DiA. Two to three months later, muscles were teased into small bundles and mounted on slides in $90 \%$ glycerol.

Repeated visualization of endplate ACh receptor density and nerve terminals. The method for in vivo imaging of neuromuscular junctions has been described previously (Lichtman et al., 1987; van Mier et al., 1994). In double nerve crush muscles, endplates were viewed $8 \mathrm{~d}$ after the second nerve crush. This is approximately in the middle of the time when junctions are likely to be innervated by more than one axon (Rich and Lichtman, 1989a). Receptors were labeled by applying tetramethylrhodamine conjugated to $\alpha$-bungarotoxin "r-btx" (Molecular Probes; 5 $\mu \mathrm{g} / \mathrm{ml}$ in lactated Ringer's solution) over the surface of the muscle for 5 min. Quantitative analysis of the intensity of fluorescence (Turney et al.,
1996) indicates that 5 min of labeling binds $\sim 30 \%$ of the bungarotoxin binding sites, which is insufficient to cause neuromuscular transmission blockade (Lingle and Steinbach, 1988). Motor nerve terminals were stained by applying a $1 \mu \mathrm{M}$ solution of 4-Di-2-Asp (Molecular Probes) (Lichtman et al., 1987) to the surface of the muscle for $30 \mathrm{sec}$. Neuromuscular junctions monitored in situ were imaged with both $25 \times, 0.6$ numerical aperture (NA), and $50 \times, 1.0 \mathrm{NA}$ water immersion "fluoreszenz" objectives (Leitz, Wetzlar, Germany). Images were obtained using a silicon-intensified target camera (series 66, Dage-MTI, Inc.) and a digital image processor (Trapix, Recognition Concepts, Inc.) as described previously (van Mier et al., 1994). Only junctions on the superficial surface of superficial muscle fibers were selected for imaging. After imaging, the wound was sutured with $6-0$ silk, and the animals were allowed to recover. Fourteen days after the first view, when synapse elimination was complete, neuromuscular junctions were restained, and the junctions that were imaged at the first view were relocated and imaged again.

Lectin labeling of the asymmetric form of acetylcholinesterase. Fluorescein conjugates of the lectin VVA-B B $_{4}$ Sigma, St. Louis, MO) were used to label the asymmetric form of acetylcholinesterase at the neuromuscular junction (Scott et al., 1988). Although VVA also labels at least one glycolipid in the postsynaptic membrane (Scott et al., 1988), we found that its staining pattern was very similar to that obtained with antiacetylcholinesterase antibodies. The fluorescently tagged lectin was used at a concentration of $50 \mu \mathrm{g} / \mathrm{ml}$ for $30 \mathrm{~min}$ in living tissue and $5 \mu \mathrm{g} / \mathrm{ml}$ for $20 \mathrm{~min}$ in fixed tissue.

To study the location of three molecules (i.e., AChRs, VVA binding sites, and any other marker), we used the technique of "overstaining." In particular, we took advantage of the staining properties and intensity of VVA sites versus $\alpha$-bungarotoxin sites. Using double labeling with two fluorophores, we found that all AChR-positive sites were also VVApositive but that there were VVA-positive sites in which AChRs were no longer present (see Fig. 3). Thus, if we stained and imaged the AChRs with FITC-btx before applying FITC-VVA, we could discern sites that were VVA-positive but AChR-negative. In addition, the FITC-VVA staining intensity was at least threefold greater than the FITC-btx staining so that the VVA signal swamped the previously recorded $\alpha$-bungarotoxin sites. Thus, although FITC-btx can contribute to a slight 

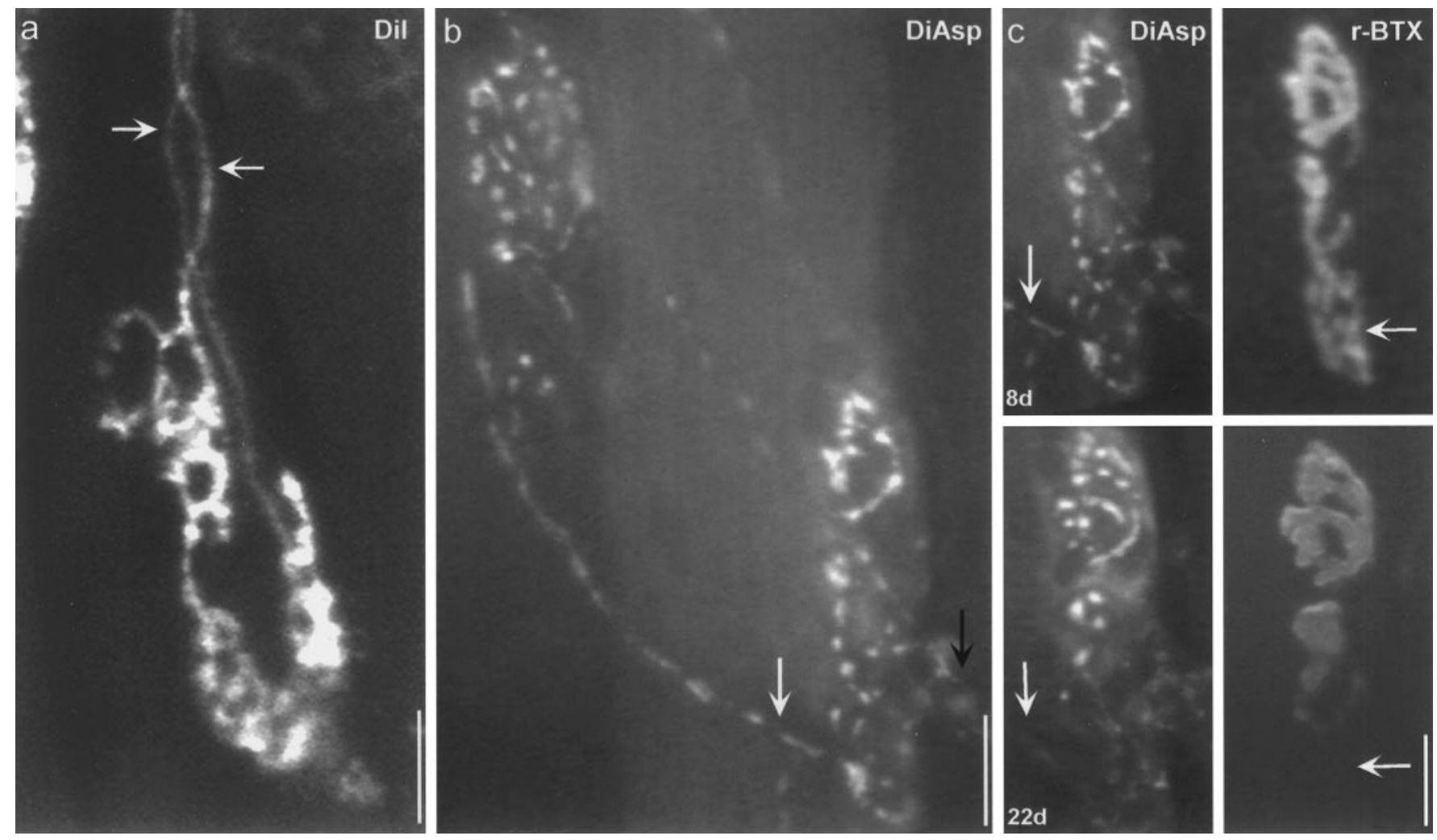

Figure 1. Elimination of multiple innervation after reinnervation. After double nerve crush, multiple axons converge on the same neuromuscular junction. The axons reach the junction either from the same direction (a, arrows indicate two DiI-labeled axons) or from different directions, one input after the old Schwann cell sheath $(b$, black arrow) and the other sprouting from a neighboring junction $(b$, white arrow). The sprouts are transient, as indicated by viewing the same junction multiple times. Shown in $b$ is a vitally stained (4-Di-2-ASP) neuromuscular junction $8 \mathrm{~d}$ after the second of two nerve crushes. Twenty-two days later, the sprout is gone ( $c$, arrow, top left; bottom panels show 4-Di-2-ASP staining of nerve terminals). The loss of the sprout is accompanied by removal of AChRs at its site of contact (c, arrows, top right; bottom panels showing r-btx staining of postsynaptic AChRs). Scale bars, $20 \mu \mathrm{m}$.

increase in the VVA signal intensity, it will not contribute to sites identifying regions of synaptic remodeling. The third epitope was stained using CY-3-conjugated secondary antibodies.

Immunocytochemistry in whole-mount muscle preparation. To identify sites of synapse loss, it is necessary to view neuromuscular junctions en face. To stain with antibodies in whole-mount muscle preparations, we have modified the immunohistochemical labeling procedure of Froehner et al. (1990) as follows. After a lethal injection of pentobarbital $(10 \mathrm{mg}$, i.p.), mice were perfused transcardially with lactated Ringer's solution (Travenol). A second perfusion with $4 \%$ paraformaldehyde was used for S-100 labeling. The sternomastoid muscle was exposed and fixed with a topical application of PLP fix (1\% paraformaldehyde, $100 \mathrm{~mm}$ lysine, and $10 \mathrm{~mm}$ sodium meta-periodate, with $0.1 \%$ saponin in PBS; or $4 \%$ paraformaldehyde, $100 \mathrm{~mm}$ lysine, and $10 \mathrm{~mm}$ sodium meta-periodate) for 15-20 min at room temperature. Excess fixative was rinsed from the neck with PBS, and the muscle was removed. The superficial surface of the muscle was dissected away from the underlying fibers to reduce background autofluorescence, and the muscle was pinned flat in a Sylgardcoated dish. After a gross dissection to remove connective tissue from the surface of the muscle, the muscles were incubated with type I collagenase $\left(1 \mathrm{mg} / \mathrm{ml}\right.$ in lactated Ringer's solution; Sigma) at $37^{\circ} \mathrm{C}$ for 10 $\mathrm{min}$. The fix was inactivated by a $10 \mathrm{~min}$ incubation at room temperature with $0.1 \%$ sodium borohydride. Acetylcholine receptors were labeled with FITC- or r-btx ( $5 \mu \mathrm{g} / \mathrm{ml}, 10 \mathrm{~min}$; Molecular Probes) before membrane permeabilization (1\% Triton-X in PBS, $10 \mathrm{~min}$ ). Nonspecific background was reduced by a $30 \mathrm{~min}$ incubation with $5-10 \%$ normal goat serum (NGS) or $10 \%$ bovine serum albumin (BSA) in PBS before antibody labeling.

All antibodies (Table 1) were diluted in either 1\% NGS or 1\% BSA in PBS and centrifuged for $10 \mathrm{~min}$ before application to remove any precipitate. Whole-mount muscle preparations were incubated with primary antibodies for $2 \mathrm{hr}$, rinsed in PBS, and then labeled with an appropriate secondary antibody for $1 \mathrm{hr}$ at room temperature. After a final rinse with PBS, muscles were mounted in Vectashield (an antifade agent; Novacastra Labs) and stored at $-20^{\circ} \mathrm{C}$.

\section{RESULTS}

\section{Synapse elimination after reinnervation}

To study the molecular alterations that occur during synapse elimination, we have investigated the large synapses of the neuromuscular junction in the sternomastoid muscle of adult mice. In the sternomastoid, synapse elimination has already been observed after nerve regeneration in adult animals (Rich and Lichtman, 1989a). To confirm and elaborate this finding, we have used lipophilic dyes and vital imaging techniques. Using DiI or DiA to anterogradely label axons and nerve terminals, we found that 12-18 d after the second of two nerve crushes (double nerve crush), junctions were contacted by more than one axon in $54 \%$ of cases ( $n=81$ of 150 junctions). In normal adult muscles, we found no multiple innervation ( $n>250$ junctions). The multiply innervated junctions fell into two categories. In $30 \%$ of cases the two axons entered the junction from the same direction in parallel (Fig. 1a), probably navigating along the old Schwann cell sheath. In the rest of the cases, one of the inputs arrived via a sprout from a different direction (Fig. 1b).

Using vital dyes to stain the same junction multiple times, we obtained evidence showing that the loss of the neuromuscular contacts by sprouts was accompanied by a corresponding loss of the density of AChRs in the postsynaptic membrane at sites of contact (Fig. 1b,c). This evidence shows directly what was in- 

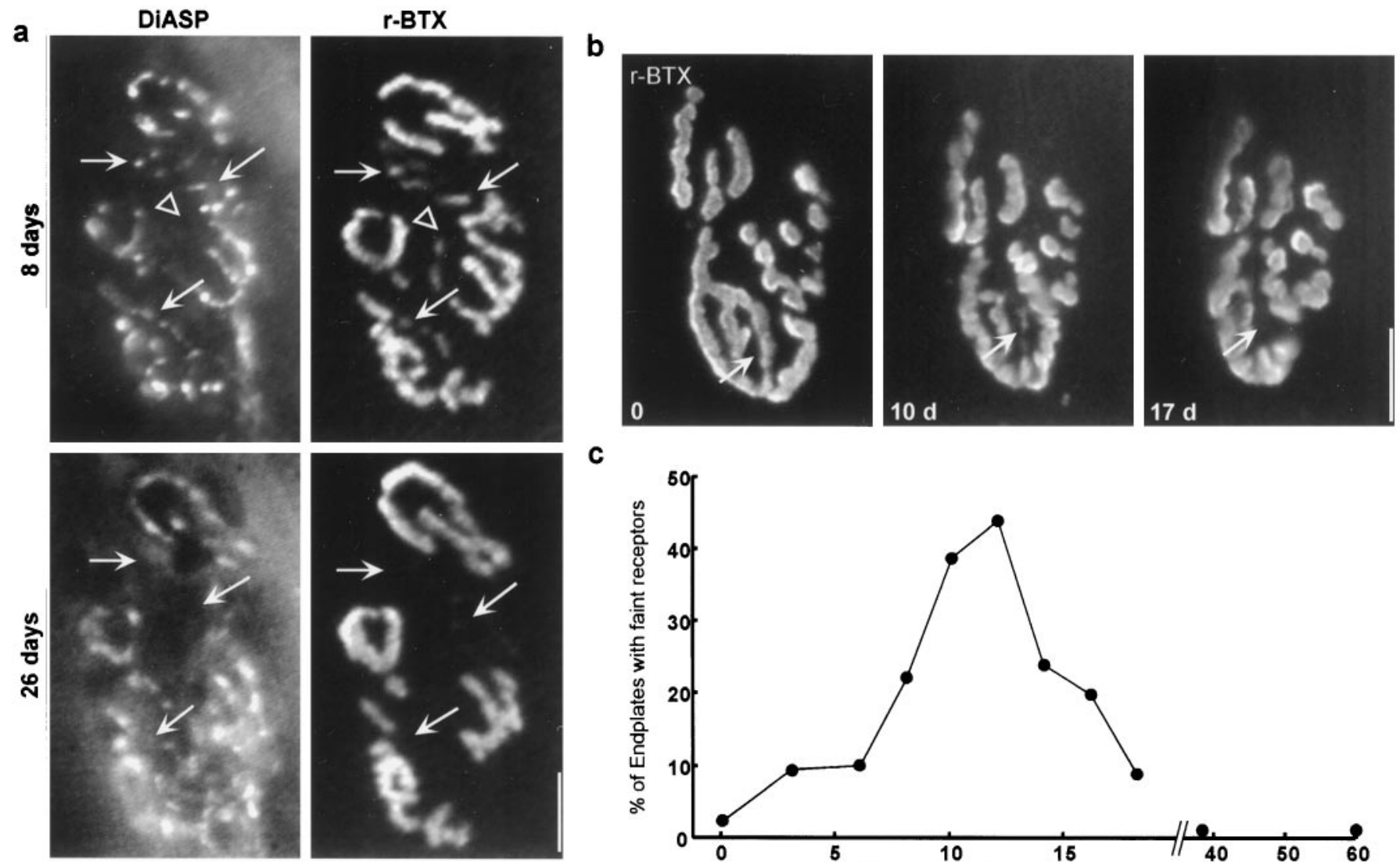

C

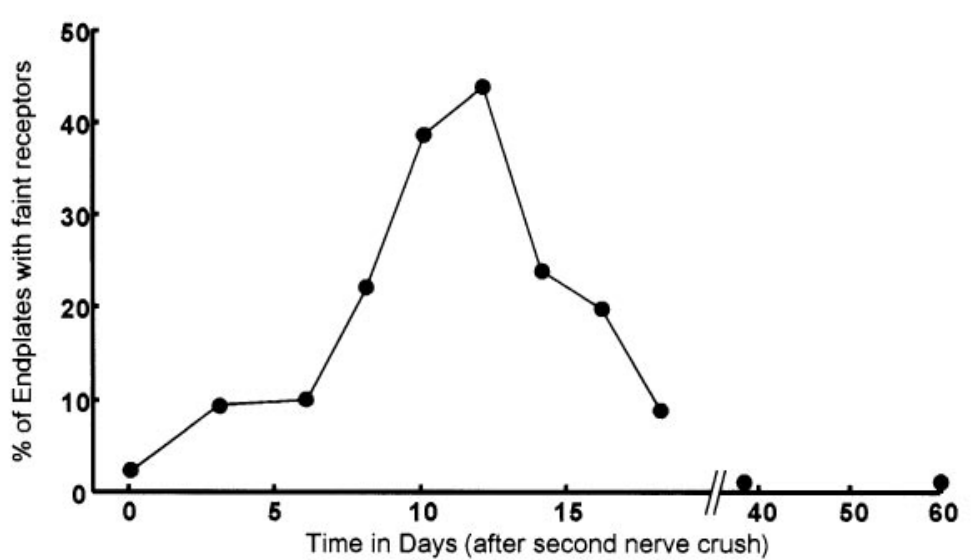

Figure 2. Reduction in AChR density at sites undergoing synapse elimination. $a$, Receptor density begins to decrease before overlying nerve terminals are removed. Eight days after the second of two nerve crushes (top panels), faint r-btx labeling (right panel, arrows) is evident at sites that are still contacted by nerve terminals (left panel, arrows). In addition, some faintly stained receptor sites (right panel, arrowhead) were not occupied by nerve terminal staining (left panel, arrowhead). Twenty-six days after the second nerve crush (bottom panels), all faint receptor regions had disappeared (right panel, arrows). At this time, nerve terminal staining is entirely missing from these former sites (left panel, arrows). $b$, The loss of AChRs from synaptic sites occurs gradually. The high density of AChRs at branches becomes modified in two ways at sites of synapse elimination. The branches become thinner, and the density of staining within the branch decreases before complete elimination $(b$, arrows). $c$, Because of the gradual elimination of receptors, the presence of faintly staining receptors is a transient marker of sites undergoing synapse elimination. Junctions were scored as having faint receptors if they had at least one region that was distinctly thinner and fainter than neighboring regions. Approximately $2 \%$ of junctions in unmanipulated muscles met these criteria. In muscles undergoing nerve regeneration, the incidence of faint receptor regions reached a peak $\sim 13 \mathrm{~d}$ after the second of two nerve crushes, and then declined toward control values. This trend mirrored the period over which muscle fibers were multiply innervated. Scale bars, $20 \mu \mathrm{m}$.

ferred in previous work (Rich and Lichtman, 1989a), that sprout withdrawal is associated with postsynaptic loss of acetylcholine receptors.

Moreover, as had been shown previously (Rich and Lichtman, 1989a), we observed a decrease in acetylcholine receptor density that began before the loss of nerve terminal staining from overlying sites (Fig. 2a). The loss of AChRs proceeded gradually. Typically, both the density of AChRs and the area occupied by faintly staining receptors becomes smaller before complete disappearance (Fig. 2a,b). From these kinds of images, we infer that axon withdrawal begins after the receptors have already begun to decrease in density. However, receptor disappearance is not complete by the time the nerve has withdrawn, so that faint receptor sites are sometimes occupied by nerve terminal staining (Fig. 2, arrows) and sometimes not occupied (Fig. 2, arrowhead).

To evaluate whether the presence of faintly stained receptor regions could therefore be used as a marker of sites undergoing synapse elimination, we assayed their incidence over time after double nerve crush. Our aim was to see whether the incidence of faint receptor regions correlated with the timing of synapse elimination. We have defined "faint" qualitatively as appearing obviously less intense than nearby regions within the same junction (Fig. 2a,b). Quantitative studies (described below) of receptor regions that appear qualitatively faint show that these areas average $55.8 \pm 2.5 \%(n=40)$ of the intensity of nearby receptor regions in the same junction. As shown in Figure $2 c$, the incidence of faintly stained receptor regions begins to increase after the axons return to the muscle ( $\sim 6 \mathrm{~d}$ after second nerve crush), peaks at $13 \mathrm{~d}$ after the second nerve crush, and then decreases over the next week. This is the same time course that we observed for the loss of multiple innervation anatomically (Rich and Lichtman, 1989a). In particular, staining nerve terminals with 4-Di-2-ASP shows abundant multiple axonal convergence at endplates between 8 and $18 \mathrm{~d}$ after the second of two nerve crushes. Between 18 and $22 \mathrm{~d}$ the incidence of sprouts drops, so that by day 22 no sprouts could be detected in $>90 \%$ of muscles (19 of 21 animals). The temporal correlation of faintly staining receptor regions and sprout retraction and the fact that the receptor changes occur very early in the process make signs of faintly staining receptor regions useful 
markers of sites that are either in the process of or have recently undergone axon withdrawal.

Furthermore, multiple views of reinnervated junctions having faint receptor regions indicated that faint sites do not recover receptor staining once receptors have begun to disappear. Rather, in all cases $(n=22)$, regions of faint receptor staining that were identified 8-9 d after the second of two nerve crushes had completely lost r-btx binding sites $4-8$ d later. This suggests that synapse disassembly is irreversible once it gets under way.

\section{Sites that have undergone synapse elimination can be identified with a lectin}

Although synapse elimination sites can be temporarily identified by faintly labeled AChRs, these sites can no longer be identified with either receptor or nerve staining once synapse elimination is complete. However, we observed that binding of the lectin VVA-B $_{4}$ is maintained at these sites (Fig. $3 a$ ). VVA-B V labels $_{4}$ $N$-acetylgalactosamine $\beta$-terminal saccharide moieties, which are present at the neuromuscular junction on the asymmetric form of AChE and at least one other glycolipid (Scott et al., 1988). Because the pattern of VVA labeling corresponds to the distribution of AChRs before synapse elimination (Fig. 3a), sites of synapse loss after nerve crush can be identified as areas within a junction that lack AChRs but stain with VVA.

One interesting difference in the VVA staining pattern at sites that are AChR-positive and those that are AChR-negative concerns the presence of "railroad tracks." In living (but not in fixed) material, sites of VVA staining where AChRs are present show a track pattern (Fig. 3a, right panel, bottom), whereas sites where VVA stains but AChRs are gone show a "filled in" pattern (Fig. $3 a$, right panel, top). A possible explanation for this staining difference is that, in living tissue, the nerve terminal blocks access to sites in the synaptic gutter (giving a railroad track pattern where nerve is present), but VVA has access to areas where the nerve has withdrawn (Rich and Lichtman, 1989a,b). Interestingly, in normal adult muscles we found a low level ( $\sim 10 \%$ of junctions) in which one typically very small isolated region was VVApositive but AChR-negative. These sites were also filled in. This is consistent with a low level of synaptic remodeling in normal animals (Rich and Lichtman, 1989a; Wigston, 1989; Hill et al., 1991; Balice-Gordon and Lichtman, 1993).

After reinnervation, when the proportion of junctions that had lost nerve terminals and AChRs from some sites was high, we located VVA+/AChR - junctional branches to examine the distribution of molecules at sites that had likely undergone synapse elimination in the previous weeks. Although the VVA trace of former synaptic sites could be used for several weeks after AChR loss, it, too, was not permanent (Fig. 3b). By 1-2 months after double nerve crush the number of junctions that had VVA+/ $\mathrm{AChR}-$ sites decreased, indicating that this marker is eventually removed from sites of synapse loss.

\section{Postsynaptic molecules are lost from sites of synapse elimination and at different rates}

To evaluate whether other components of the postsynaptic site are also removed at sites of synapse elimination, we have surveyed the distribution of six molecules (rapsyn, phosphotyrosine residues, $\epsilon$ subunit of the AChR, utrophin, syntrophin, and dystrophin) that are concentrated at the neuromuscular junction. We compared their distribution between junctions in normal adult animals and in animals undergoing synapse elimination after nerve crush.
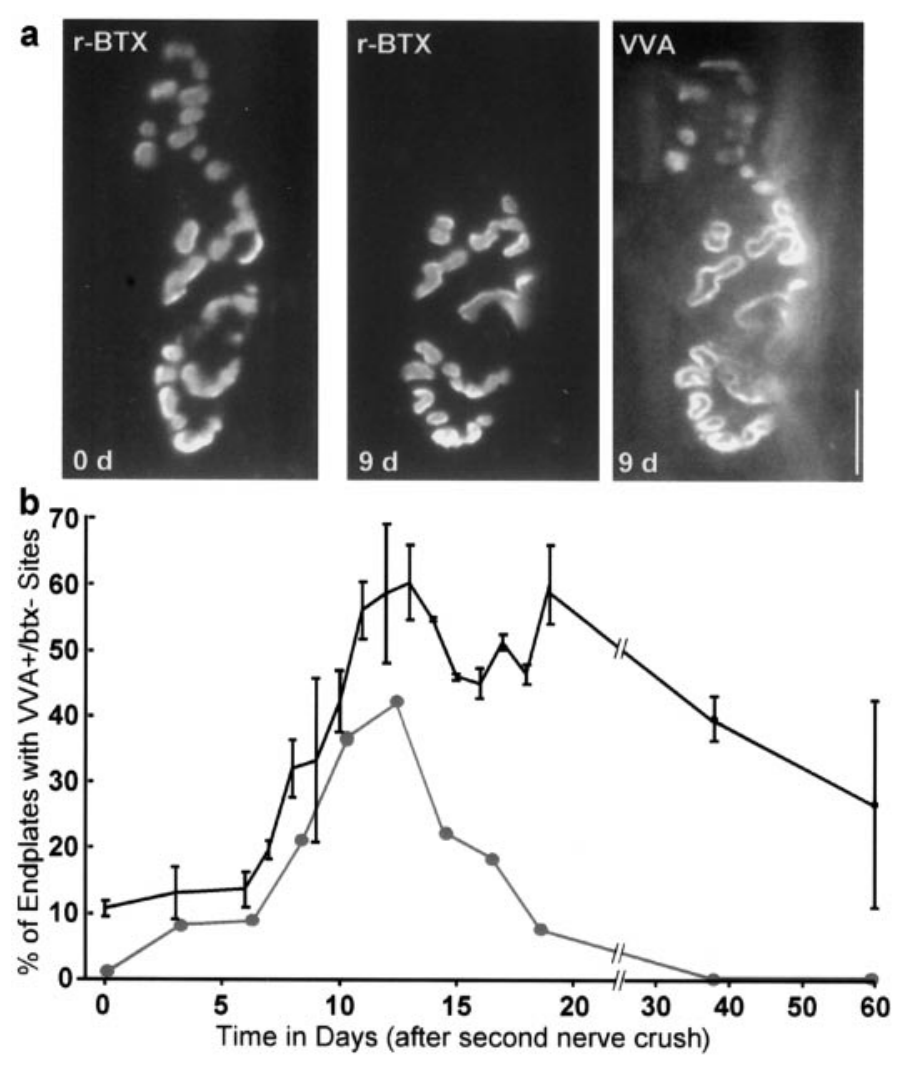

Figure 3. Persistence of lectin labeling at sites of synapse loss. Multiple views of the same neuromuscular junction after nerve regeneration after double nerve crush show that sites that lose AChRs maintain labeling with the lectin VVA $(a)$. The top portion of this junction has lost all evidence of receptors $9 \mathrm{~d}$ after the second of two nerve crushes. In contrast, the lectin staining is still evident, although it no longer displays the railroad track pattern seen at sites in which nerve terminals are still present (compare top and bottom regions of the VVA labeling). The loss of VVA label at sites of synapse elimination is protracted (b). More than 1000 neuromuscular junctions from normal muscles $(0 \mathrm{~d})$ or in muscles various times after the second of two nerve crushes ( $n=47$ muscles) were examined. The number of junctions with $\mathrm{VVA}+/ \mathrm{btx}-$ sites, which is indicative of synapse loss ( $\operatorname{see} a$ ), were tallied and expressed as a percentage of the total number of junctions analyzed in each muscle. This percentage increases progressively, peaking between 13 and $19 \mathrm{~d}$. However, in distinction to faint receptor staining (Fig. $2 c$; replicated here in gray), which drops quickly, the VVA labeling only declines very gradually. Even $60 \mathrm{~d}$ after double nerve crush, there is still a substantial number of junctions with mismatched staining. These data indicate that VVA can be used to identify sites of synapse loss for $\sim 3$ weeks after the second of two nerve crushes. Scale bar, $20 \mu \mathrm{m}$.

Figure 4 shows the distribution of these six synaptic markers in normal adult neuromuscular junctions labeled in whole mount. For each molecule, the distribution at the junction closely matches the distribution of AChRs. In addition, two of these constituents, syntrophin and dystrophin, are also present along the entire length of the plasmalemma (data not shown). A total of 13-142 normal junctions (from 4-13 animals) were studied for each probe, and the staining was highly consistent.

To determine whether any of these molecules are altered at sites where axons withdraw, we have surveyed the distribution of these same markers in muscles $11-17 \mathrm{~d}$ after the second of two nerve crushes (10-255 junctions from 4-46 animals). The sites of synapse elimination were determined, as described above, by the presence of VVA staining at sites where AChRs were no longer present. 


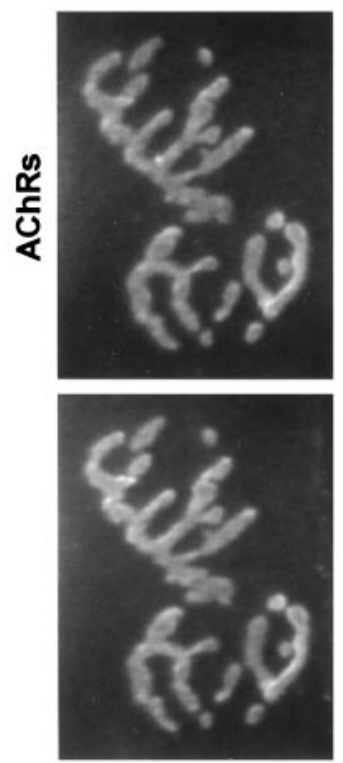

RAP
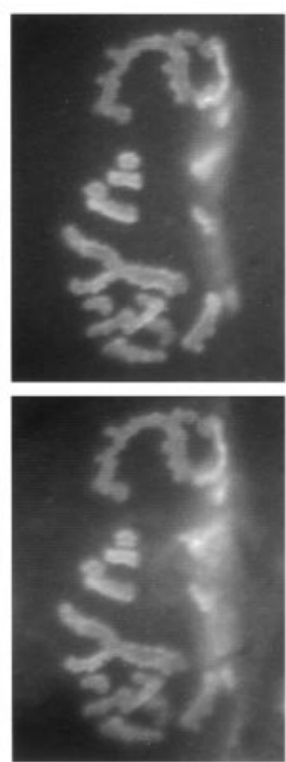

PT
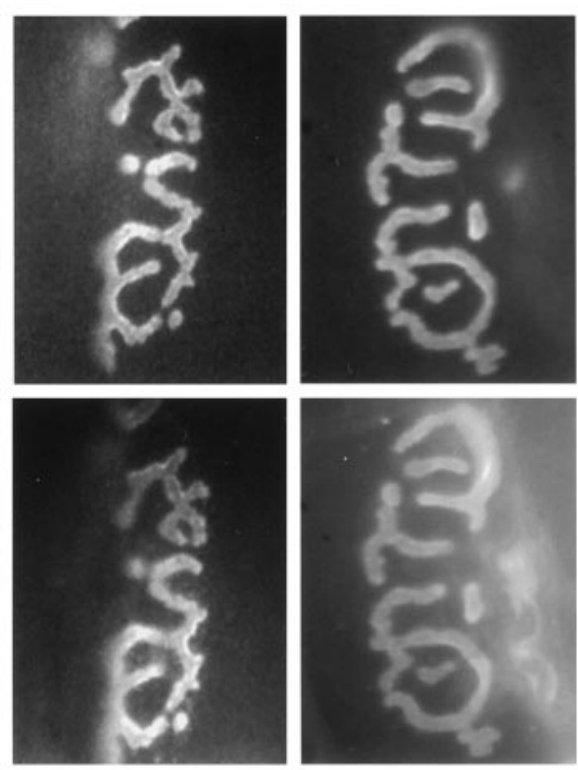

EpS

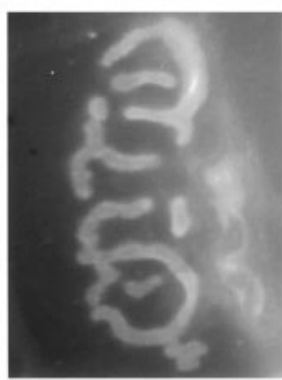

UTR
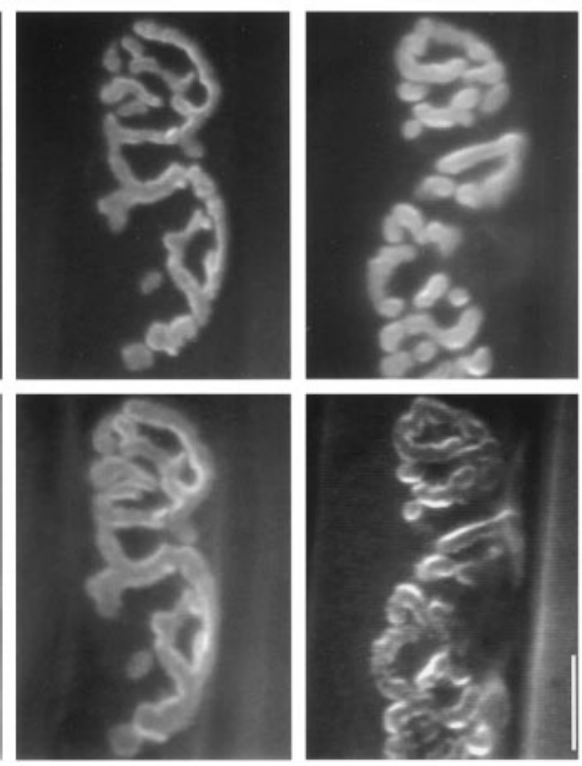

SYN

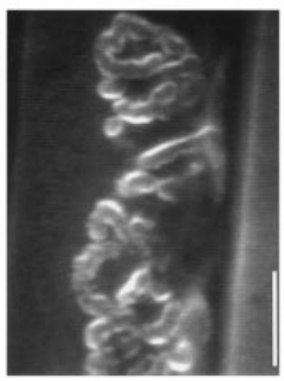

DYS

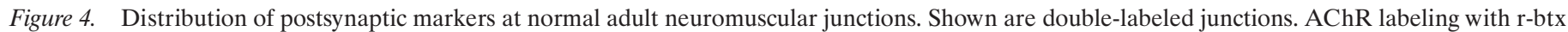

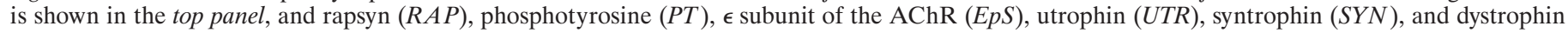
$(D Y S)$ are shown in the bottom panels. These markers colocalize with AChRs at the postsynaptic site. Scale bar, $20 \mu \mathrm{m}$.

Two of the markers, dystrophin and syntrophin, were clearly still present in high density at sites where AChRs had been lost (Fig. 5). Thus, these molecules were not being removed from the former synaptic sites in the same way as AChRs. At long times after reinnervation when $\mathrm{VVA}+/ \mathrm{AChR}$ - sites were less common, we found no evidence of high-density dystrophin or syntrophin staining at sites lacking VVA. This staining pattern suggests that these molecules are being removed at approximately the same rate as VVA staining.

In distinction to syntrophin and dystrophin, all of the other muscle markers we studied (rapsyn, phosphotyrosine, $\epsilon$ subunit, and utrophin) were lost quickly at sites undergoing synapse elimination (Fig. 5). The loss of these agents at sites of synapse elimination was not simply a consequence of removal of the overlying nerve terminal. In 17 animals, viewed $2 \mathrm{~d}$ to 2 weeks after neuromuscular junctions were denervated by cutting the nerve, we stained for the same molecules (Fig. 6). In none of these cases did we find loss of any of these markers.

Not all of the markers that disappeared rapidly were lost at the same rate. In particular, utrophin staining was sometimes (7 of 43 cases) still relatively concentrated at sites where AChRs were nearly completely lost (Fig. 7). In the remaining 36 of 43 cases, either both AChRs and utrophin were no longer visible or both were equally faint. This suggests that utrophin begins to disappear at a slower rate than AChRs but that eventually both molecules are lost.

\section{Several molecules disappear at the same rate as AChRs}

An important question was whether rapsyn or phosphorylated tyrosine residues, which have been associated with the regulation of the postsynaptic accumulation of AChRs (see Discussion), were lost before AChRs at junctions undergoing synapse elimination. Such early changes might indicate that one of these molecules was instrumental in causing AChRs to be lost and thus a very early step in the cascade that leads to the removal of the specialization.

Because we observed no qualitative difference in the distribution of rapsyn and AChRs at endplates that had undergone synapse loss, we wanted to address with higher-resolution methods whether there was any evidence that loss of one molecule preceded the loss of the other. Branches in the process of undergoing synapse elimination were identified (by the presence of faint r-btx staining) in muscles $12-14 \mathrm{~d}$ after the second of two nerve crushes, when junctions with faint receptor regions were most prevalent (Fig. 2b). Faint AChR staining was quantified by obtaining a ratio of the intensity of the faint area to a maintained area within the same junction (Fig. 8a,c, inset). The ratio for AChR staining (ratio r-btx $=$ intensity of faint site/intensity of maintained site) was $53.3 \pm 3.8 \%( \pm \mathrm{SEM} ; n=21$ endplates $)$. The ratio of rapsyn staining was calculated the same way as for r-btx at the same sites in doubly labeled junctions. The amount of loss of rapsyn was similar to that of AChRs; the ratio of faintly stained rapsyn regions relative to staining at the maintained sites was $53.8 \pm 3.6 \%$. Furthermore, when the loss of AChRs was compared directly with the loss of rapsyn within individual endplates, we found that the amount of loss for each probe was virtually identical at faint sites (ratio r-btx/ratio rapsyn $=1.05 \pm 0.08$; Fig. $8 b)$. A third analysis compared a pixel-by-pixel scatter plot of rapsyn with $\mathrm{AChR}$ labeling in a faint area of an endplate with a representative maintained area. If the two molecules were being differentially lost from faint areas, then the slope of the scatter plot should be different for faint areas than for normal areas. When we did this analysis we found no systematic difference in the slopes of the plots from faint and normal regions of the same junctions (Fig. 8c). Taken together these results suggest that rapsyn and $\mathrm{AChRs}$ are lost from synaptic sites at the same rate, indicating that the loss of these two molecules from synaptic sites is closely coupled. 

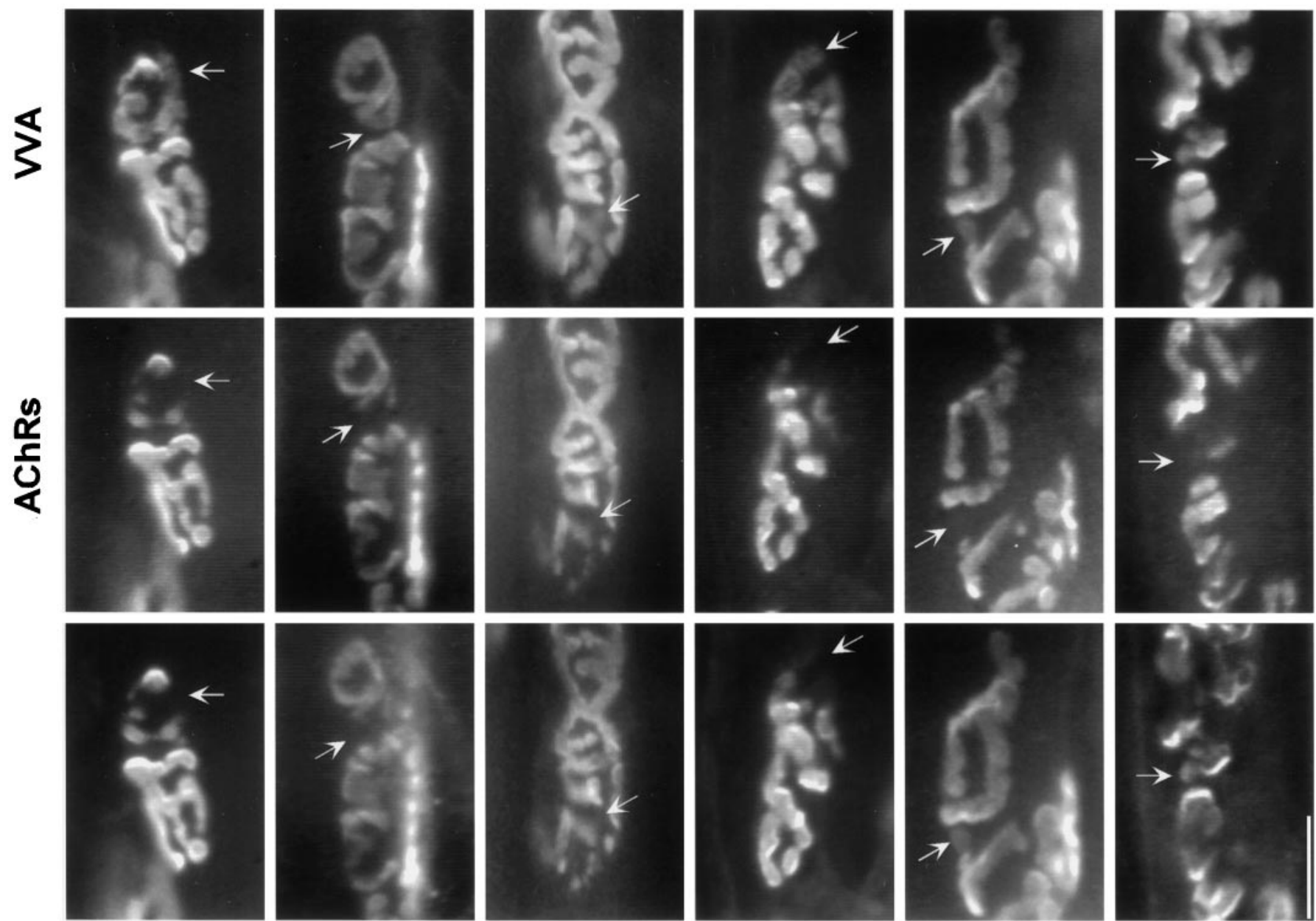

RAP

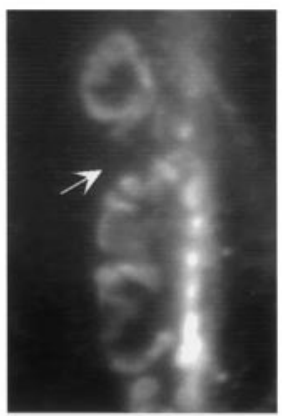

PT

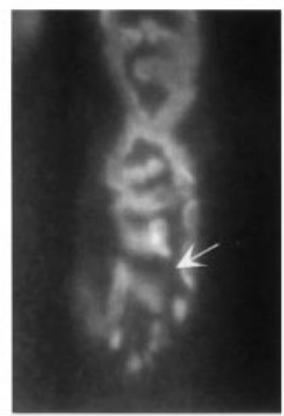

EpS

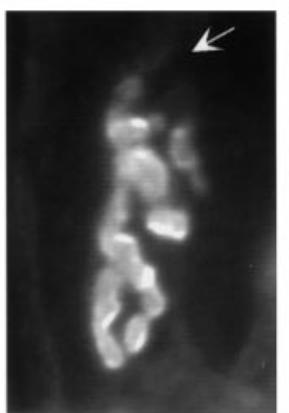

UTR

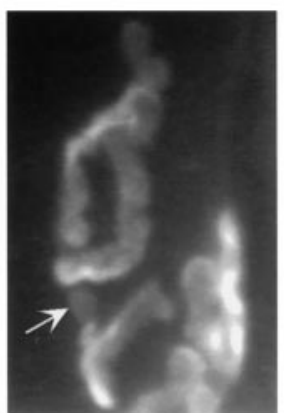

SYN

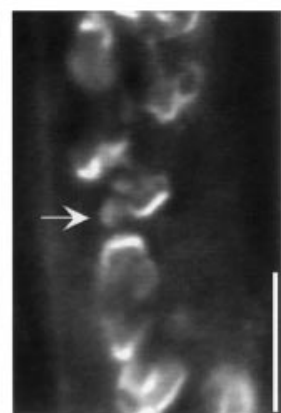

DYS

Figure 5. Distribution of postsynaptic markers at neuromuscular junctions that have undergone synapse loss. Former synaptic sites [labeled with the lectin VVA (top panels) but have lost AChRs (middle panels)] are indicated by the white arrows. In addition to the AChR, four other markers [rapsyn $(R A P)$, phosphotyrosine $(P T), \epsilon$ subunit $(E p S)$, and utrophin $(U T R)]$ were missing from sites that had undergone synapse elimination. In contrast, syntrophin $(S Y N)$ and dystrophin $(D Y S)$ remain at sites that have lost AChRs. Scale bar, $20 \mu \mathrm{m}$.

A similar analysis of the loss of phosphotyrosine (PT) labeling at sites undergoing $\mathrm{AChR}$ loss showed that there was no significant difference in the rate of loss of the two markers. The average brightness of faint receptor regions was $54.8 \pm 4.6 \%(n=7)$ of the brightness in areas that were being maintained, whereas PT staining in those same regions was on average $53.7 \pm 8.0 \%$. Similarly, there was no difference observed when the comparison of the loss of AChRs with the loss of PT was made on an endplate-by-endplate basis (ratio r-btx/ratio PT, $1.10 \pm 0.10$ ).

Because both $\gamma$ and $\epsilon$ subunits are transiently present during developmental synapse elimination and synapse elimination in adults after denervation ( $\mathrm{Gu}$ and Hall, 1988), we asked whether there was a specific change in the amount of $\epsilon$ subunit at sites that were undergoing loss. Any difference in the distribution of the $\alpha$ subunit (which is present in both $\epsilon$ - and $\gamma$-containing receptors and is bound by bungarotoxin) versus the $\epsilon$ subunit in faint AChR areas compared with normal areas would suggest that the $\epsilon$ subunit was being differentially regulated at sites of synapse elimination. Analysis of the intensity of r-btx labeling and anti- $\epsilon$ subunit staining in faint receptor areas indicated that $\epsilon$-containing AChRs were being lost from eliminated sites at a rate that was not significantly different from $\alpha$ subunits $(60.9 \pm 5.0 \% ; n=9$ for bungarotoxin staining; and $65.9 \pm 5.8 \%$ for anti- $\epsilon$ labeling). When the comparison of the ratio of bungarotoxin staining to anti- $\epsilon$ staining was made on an endplate-by-endplate basis (ratio r-btx/ratio $\epsilon$ subunit), we also found no statistically significant difference in the ratio of the two labels $(0.91 \pm 0.08)$ when compared with normal endplates $(1.16 \pm 0.22 ; n=5 ; p=0.3)$.

\section{Several extracellular markers are maintained at sites of synapse elimination}

As shown above, components that bind the lectin VVA (including acetylcholinesterase; Scott et al., 1988) remain for relatively long times at sites that have lost nerve terminals and receptor staining as a consequence of synapse elimination. The maintained VVA staining, however, may be the result of the unusual stability of esterase in the extracellular space. In frog, for example, acetylcholinesterase labeling remains at denervated junctions for at least 2 years (Krause and Wernig, 1985). To see whether other extracellular markers that are concentrated at the neuromuscular junction were also maintained at sites undergoing synapse elimination, we surveyed several different agents [laminin $\beta 2$ (in rat), laminin $\alpha 5$, and neural cell adhesion molecule (NCAM)]. In normal animals each of these markers is concentrated at the 

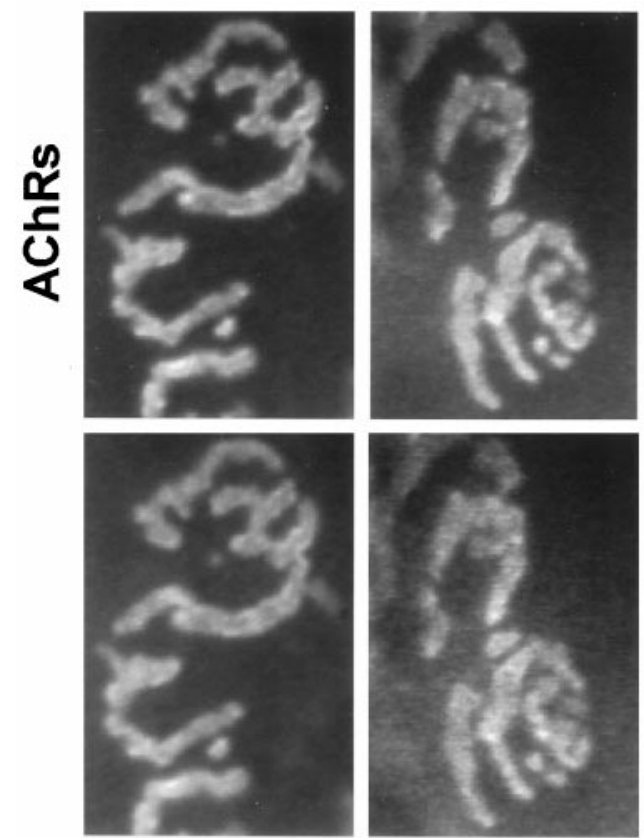

RAP

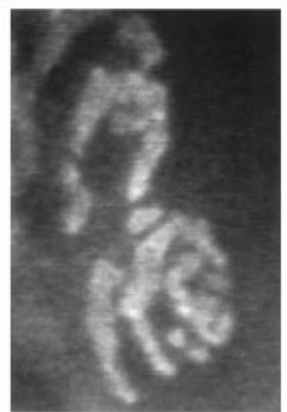

PT
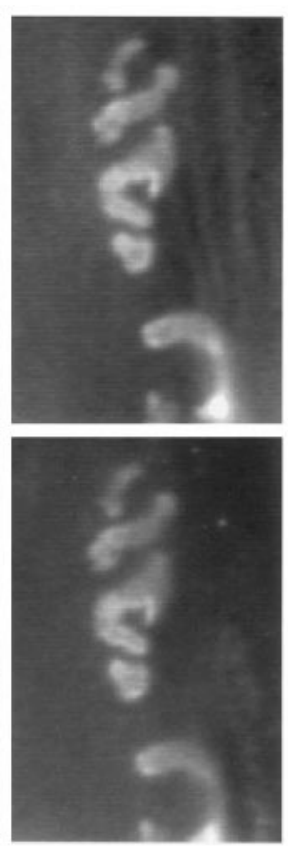

EpS
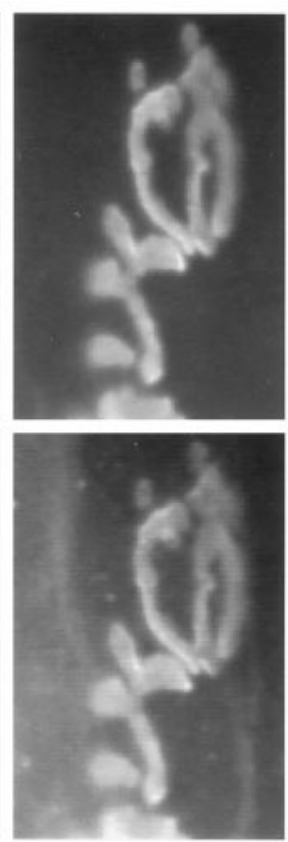

UTR
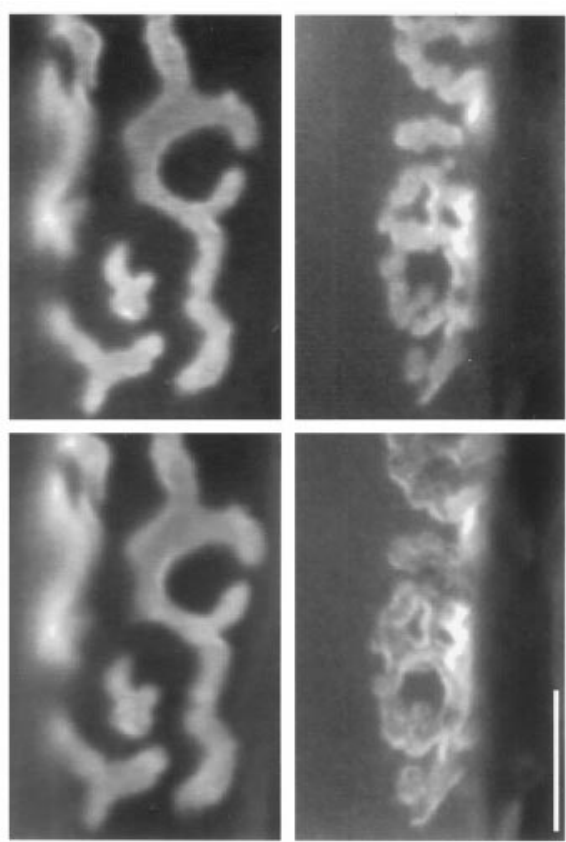

SYN

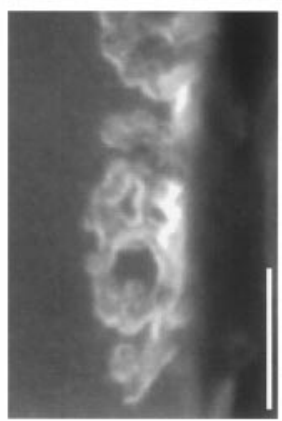

DYS

Figure 6. Distribution of postsynaptic markers at neuromuscular junctions that have been denervated. The loss of AChRs and other postsynaptic markers is not attributed to the absence of nerve terminal input. Nine to $11 \mathrm{~d}$ after denervation, AChRs (top panel) and other postsynaptic markers (bottom panel) remain concentrated at junctional sites in the postsynaptic membrane. This finding indicates that the absence of these markers at sites of synapse loss is specific to the synapse elimination process, rather than a consequence of a lack of innervation at those sites. Scale bar, $20 \mu \mathrm{m}$.

AChRs
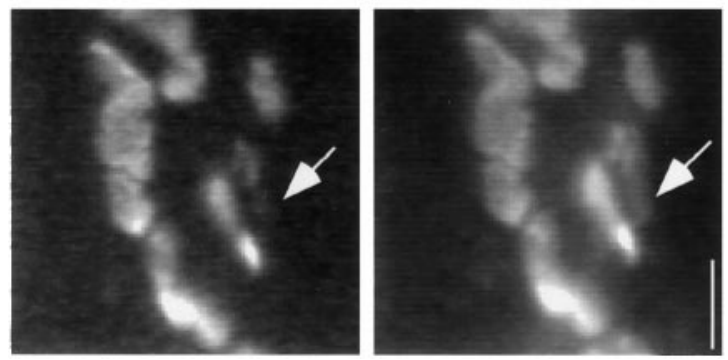

Figure 7. Delayed removal of utrophin compared with AChRs at sites of synapse elimination. Utrophin staining was sometimes more extensive than AChR labeling at sites in which AChRs were in the process of being eliminated. Because sites that have lost AChRs completely never show utrophin staining (see Discussion), this finding implies that although both utrophin and AChRs are lost from sites undergoing synapse elimination, utrophin is lost at a slightly slower rate than AChRs. Scale bar, $10 \mu \mathrm{m}$.

neuromuscular junction and grossly matched the distribution of AChRs (17-45 junctions from three to seven animals for each marker; Fig. 9). Two to three weeks after the second of two nerve crushes, labeling for these markers was evident at former sites that were AChR-negative (total of 8-18 junctions from two to five animals for each marker; Fig. 10, arrows). The maintenance of extracellular markers indicated that a number of molecules remain for some time ( $>2$ weeks) at sites undergoing synapse elimination.

\section{Schwann cell processes are quickly removed once receptors begin to disappear from sites undergoing synapse elimination}

To evaluate whether supporting Schwann cells undergo structural changes during the synapse elimination process, we stained
Schwann cell processes using antibodies against the S-100 protein. In normal junctions the Schwann cell processes coaligned with the AChRs (Fig. 11, top panels; $n=56$ junctions in 12 mice) (Woolf et al., 1992; Son and Thompson, 1995a,b). Two to three weeks after the second of two nerve crushes, 73 junctions were studied. These junctions were triple-labeled with S-100 to label Schwann cell processes, r-btx to label AChRs, and VVA to mark synaptic sites. Thirty-two of 73 junctions (43.8\%) showed complete matching of the three markers throughout. In 39 of 73 junctions $(53.4 \%)$, sites of synapse elimination were evident by the presence of VVA at branches that either lacked or had only faintly stained AChRs (17 and 22 of 73 junctions, respectively). In nearly three-quarters of these cases (29 of 73) the sites also lacked S-100 staining, suggesting that Schwann cell processes are removed from sites of synapse elimination (Fig. 11, middle panels).

To determine the time course of Schwann cell process removal relative to the loss of AChRs, we examined junctions that had faintly staining receptor regions and asked whether Schwann cell processes were present. In 15 of 22 junctions (68\%) with faint receptor regions, we found that Schwann cell processes were absent from sites where receptors were faintly stained. In these cases, it was not possible to determine whether the change in receptor density began before or followed the withdrawal of the Schwann cell process. In $31.8 \%$ (7 of 22) of junctions, however, we saw sites with faint receptor staining where S-100 staining was still present (Fig. 11, bottom panels). This staining pattern suggested that Schwann cell processes are removed after AChRs have already begun to disappear, because they were still present at sites where AChR density had already changed. Interestingly, this is similar to the time course of nerve terminal withdrawal, which also slightly lags the onset of the loss of AChRs (Fig. 2a). Consistent with this, we observed a few junctions (3 of $73,4.1 \%$ ) 
where former synaptic sites (having VVA staining but lacking AChR staining) were still contacted by Schwann cell processes. In only 2 of 73 junctions $(2.7 \%)$ did we detect receptor sites that stained normally but lacked Schwann cell processes; the significance of these sites is not presently clear. In sum, Schwann cell processes do disappear at sites of synapse elimination. Because Schwann cell staining was often found at sites that had already begun to lose AChR staining, whereas only very rarely was the reverse seen, we infer that changes in Schwann cells occur after alterations in the postsynaptic receptor density have already begun. a

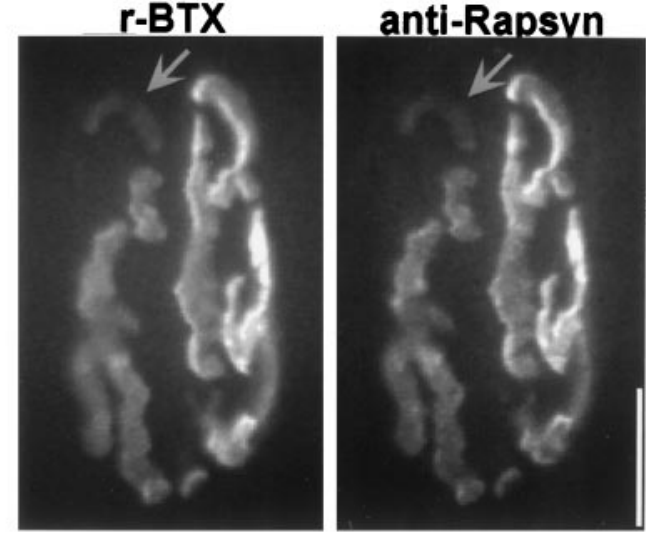

\section{b Ratio of AChR loss to Rapsyn loss}

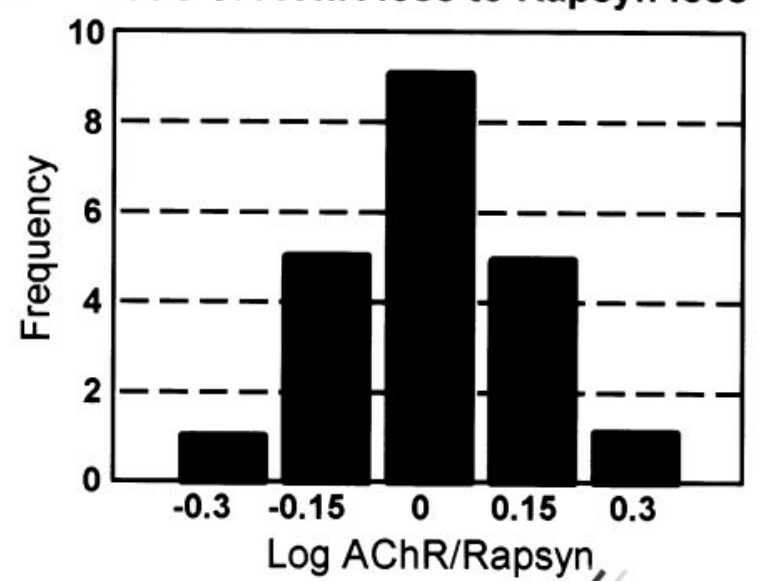

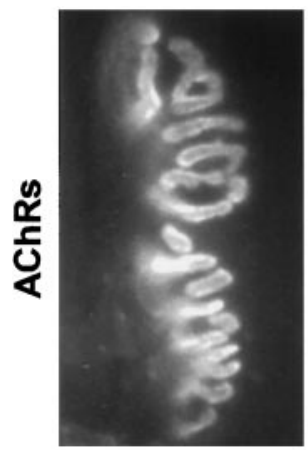
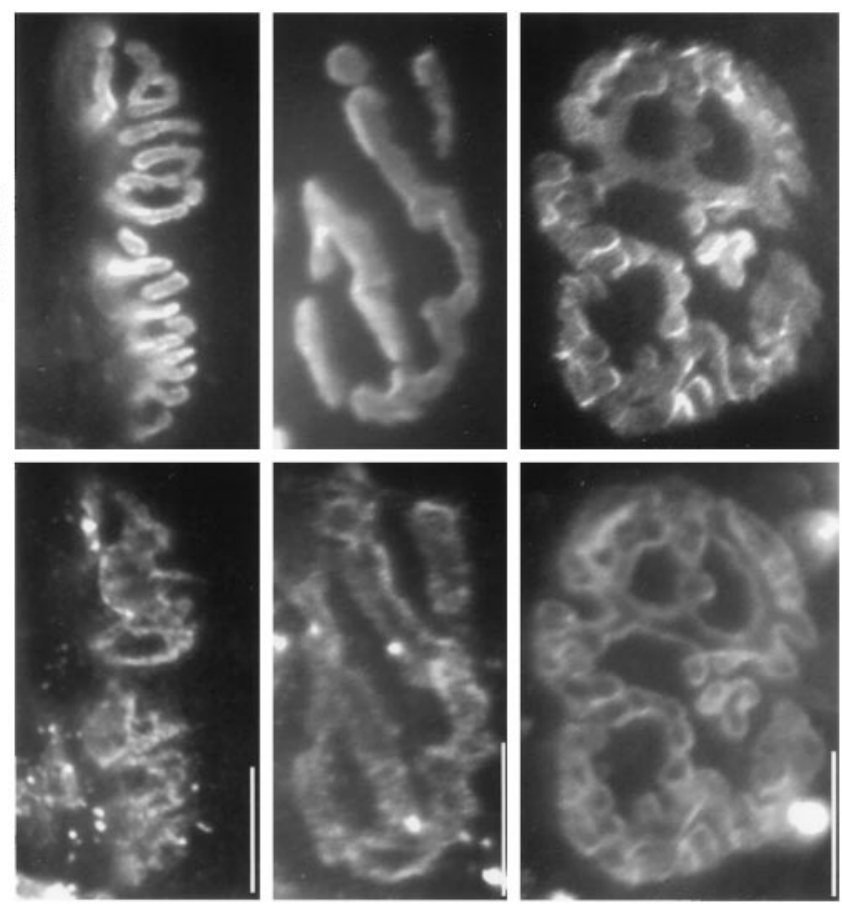

NCAM

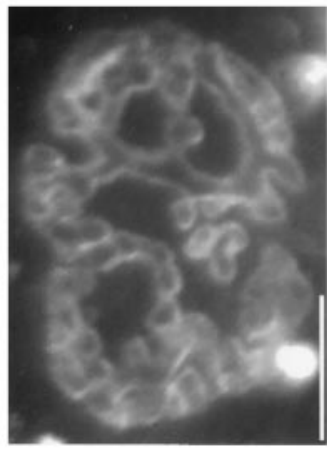

laminin $\beta 2$

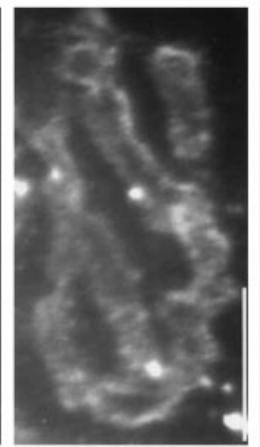

laminin $\alpha 5$
Figure 9. Distribution of extracellular markers at normal adult neuromuscular junctions. Labeling of the postsynaptic membrane for AChRs is shown in the top panels, and labeling of NCAM or laminin $\alpha 5$ in mice and laminin $\beta 2$ in rat is shown in the bottom panels. All markers are localized at sites in which AChR density is high. Laminin $\alpha 5$ and laminin $\beta 2$, which are present in the basal lamina, exhibit a railroad track staining pattern at normal junctions that is similar to VVA labeling. NCAM, which is present in nerve and muscle membrane, has a staining pattern that is slightly narrower than the distribution of AChR staining. Scale bars, $20 \mu \mathrm{m}$.

Figure 8. Synchronous removal of rapsyn and AChRs at sites of synapse elimination. $a$, Qualitatively, rapsyn staining appeared equally as faint as AChR staining at sites in which AChRs were in the process of being eliminated (gray arrows). $b$, To evaluate rapsyn and AChR staining in a more quantitative way, we calculated the percentage of label remaining at sites undergoing elimination by taking the ratio of the intensity of staining in the faint versus nearby normal regions. In particular, we compared the ratio of rapsyn to the ratio of AChR staining in the same two regions of doubly labeled junctions. If rapsyn were being lost more rapidly, this ratio should be lower for rapsyn than for AChRs. When we analyzed 21 junctions by dividing the ratio of $\mathrm{AChR}$ intensity by the ratio of rapsyn intensity in faint versus normal regions however, we found no significant difference. These data are displayed as the log so that the quotients $>1$ and $<1$ are plotted symmetrically. This result indicates that the two molecules could not be leaving the elimination site at substantively different rates. $c$, This conclusion was corroborated by another approach in which we asked whether there might be a subtle difference in the amount of rapsyn versus AChRs at sites undergoing disappearance. The intensity of the rapsyn and AChR labeling was compared pixel by pixel and was plotted for both a faint region (c, gray) and a nearby normal region $(c$, black $)$. A difference in the slopes of these two data sets would indicate that the loss of these two molecules is occurring at different rates. Whereas in most junctions we did find small differences between the slopes of the two data sets, there was no systematic effect. That is, in a compilation of all the faint areas studied in this way, there were as many examples in which the AChRs appeared to be disappearing slightly faster than the rapsyn as cases in which rapsyn was lost at a faster rate than AChRs. Scale bar, $20 \mu \mathrm{m}$. 

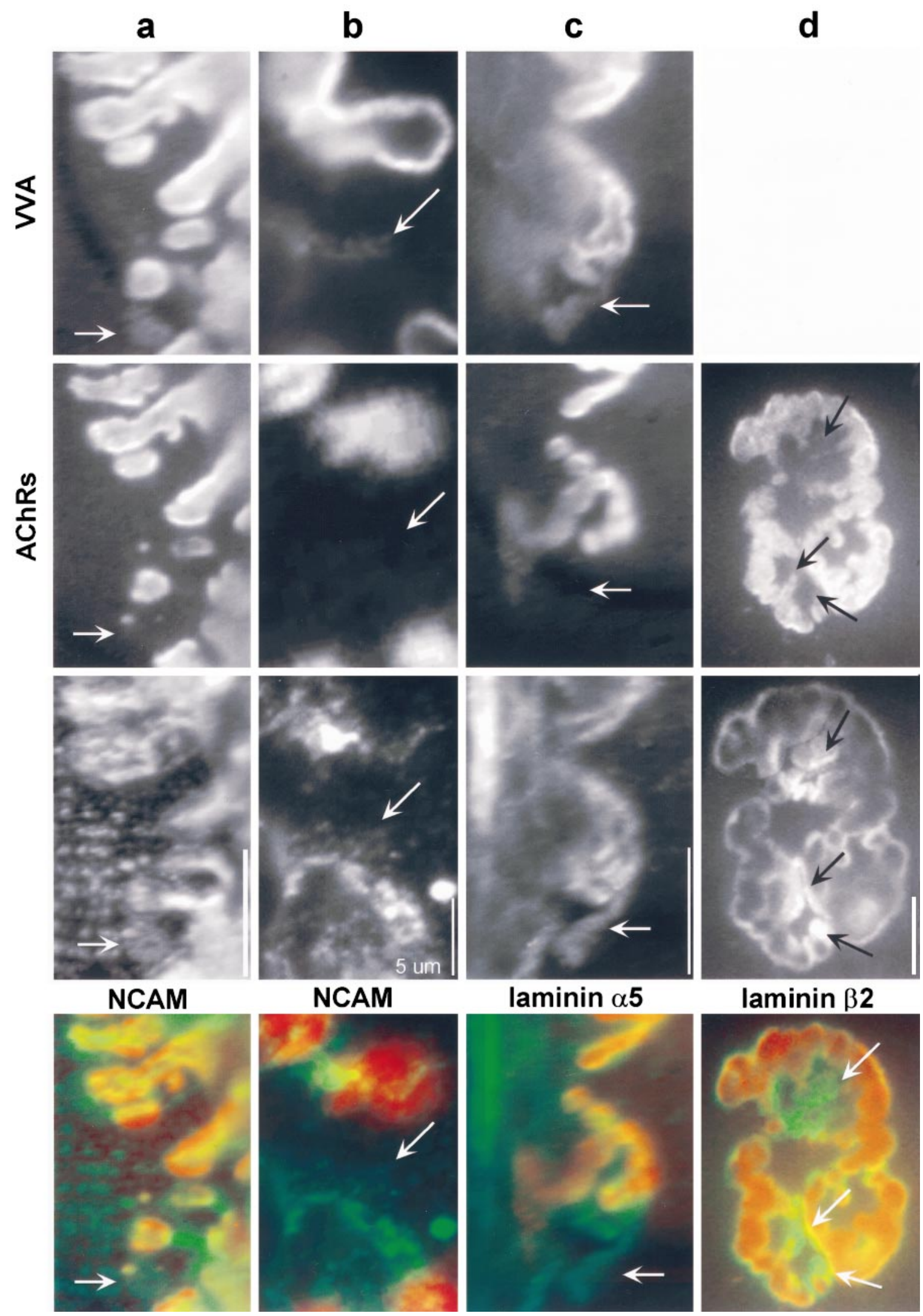


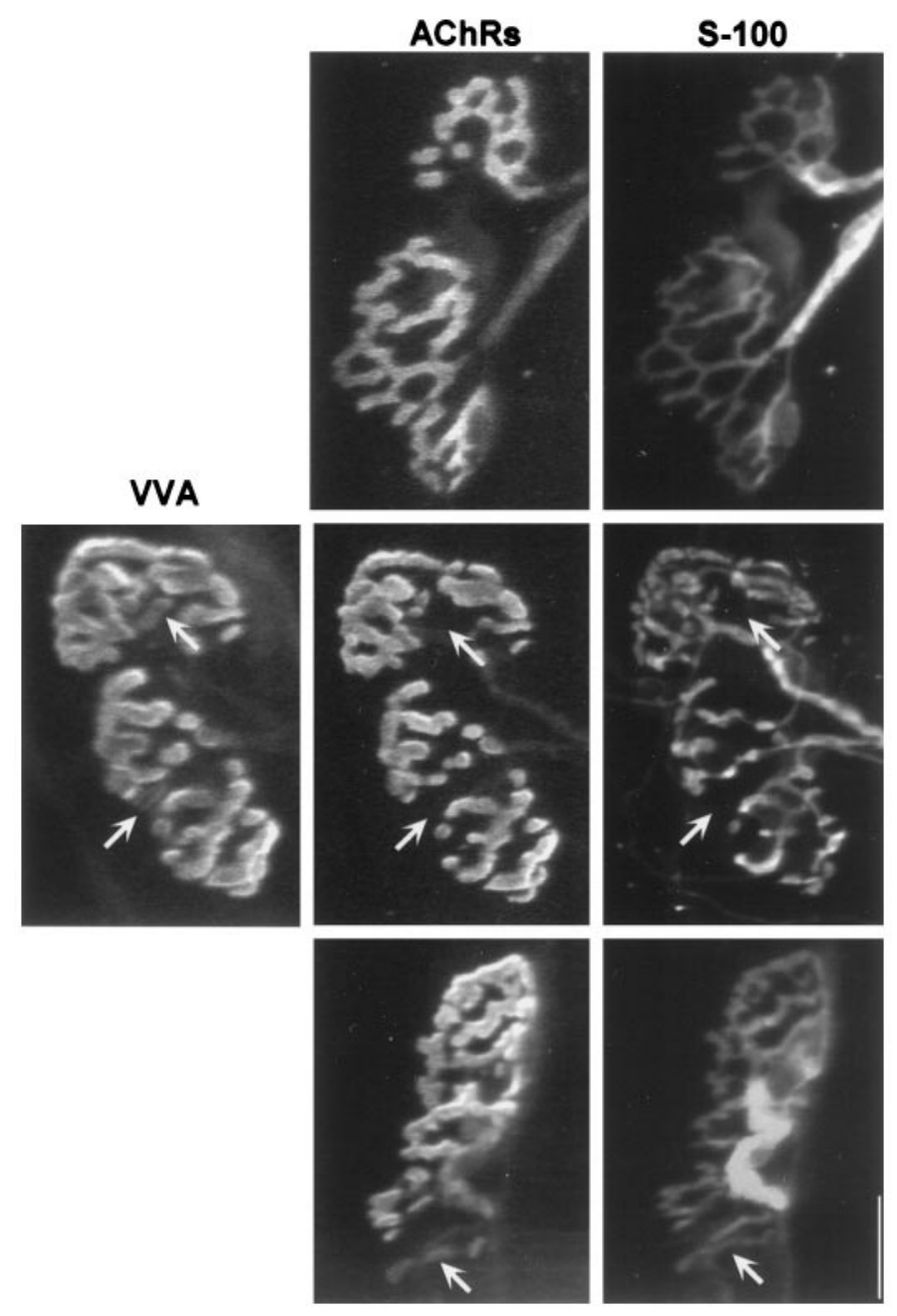

Figure 11. Delayed disappearance of Schwann cell processes at sites undergoing synapse elimination. At normal junctions, Schwann cell processes, as seen by S-100 labeling, colocalize with AChRs (top panels). At sites that have undergone synaptic loss after double nerve crush (VVA+/ AChR - sites), Schwann cell process staining has also disappeared (arrows, middle panels). To determine when Schwann cell processes withdraw from a junction relative to the loss of AChRs, we examined faintly staining receptor regions after double nerve crush (22 junctions). Although Schwann cell processes had withdrawn from areas of faint receptor staining in the majority of junctions (15 of 22), they still occupied sites that had reduced AChR density in almost one-third of cases (7 of 22 junctions; arrows, bottom panels). This finding suggests that Schwann cell process retraction occurs after AChR loss is already under way. Scale bar, $20 \mu \mathrm{m}$.

\section{DISCUSSION}

The principal aim of this work was to improve our understanding of changes that occur during the synapse elimination process. To do this, we have surveyed three aspects of the neuromuscular junction (the postsynaptic apparatus, the basal lamina, and the Schwann cell) and asked whether any of these components undergo changes at sites of synapse loss. The results show that there are substantial alterations in both the postsynaptic cell and glia at sites of synapse loss, whereas we have thus far found little evidence of rapid alteration of the basal lamina. In particular, four markers in the postsynaptic cell (rapsyn, utrophin, AChRsincluding the $\epsilon$ subunit, and phosphotyrosine) disappear rapidly, whereas dystrophin and syntrophin disappear more slowly. Several extracellular markers (NCAM, laminin $\alpha 5$, laminin $\beta 2$, and VVA staining) also remain for long times at sites of synapse elimination. Glial cell processes are also removed from sites where nerve and postsynaptic AChRs are withdrawn. Thus, the consequence of synapse elimination is a general dismantling of the synaptic site that includes alterations in nerve, muscle, and supporting cells. Given these results, it seems unlikely that axonal competitors are striving to occupy the same synaptic sites.

These results also help define the changes occurring at the neuromuscular junction related to the removal of the AChRs and withdrawal of the overlying nerve terminal. One hope was that we might find an agent that undergoes alterations before the loss of AChRs, thus implicating the agent as playing an instrumental role in getting the synapse elimination process under way. To do this we developed a technique to evaluate the relative amounts of different molecules that were present at sites that were in the process of elimination. Because different antibodies have different affinities, we always controlled for access and binding by comparing the relative amount of antibody labeling in regions undergoing synapse elimination to that in areas that were being maintained in the same junction. This ratio was then compared with that for AChR labeling in the same junctional regions. This technique normalizes for differences in affinity and access and would only be problematic in situations in which the affinity of one probe was so low that no staining was detected. However, in the only situations in which we saw absence of staining, it paralleled absence of the very-high-affinity bungarotoxin binding.

At the level of resolution of our techniques, both rapsyn and phosphotyrosine residues were removed as quickly as AChRs. Ratio imaging suggests that the disappearance of receptors and these other markers therefore occur in parallel. Because rapsyn appears to be essential for the clustering of AChRs (Froehner et al., 1990; Phillips et al., 1991; Gautam et al., 1995), its early loss could be followed quickly by AChR removal, not resolvable by our techniques. Thus the parallel loss of these two agents does not preclude the possibility that changes in the distribution of rapsyn underlie the decrease in AChR density at sites undergoing synapse elimination.

\section{$\leftarrow$}

Figure 10. The persistence of extracellular markers at junctional sites that have undergone synapse loss. Junctions were triple-labeled for VVA (top row), AChRs (second row), and NCAM or laminins (bottom rows). Color superimposition of receptor shown in red, and antibody labeling from the third row shown in green (bottom row). a, The left column shows persistence of NCAM staining at a site in a normal junction that is VVA-positive but has lost AChR staining (arrows). VVA-positive, AChR-negative sites were found in $\sim 10 \%$ of normal adult neuromuscular junctions and probably reflect a basal level of synaptic turnover (Fig. 3b). $b$, Twenty-five days after double nerve crush, the upregulation of NCAM after the denervation induced by double nerve crush (Covault and Sanes, 1985) had begun to subside, and we could observe VVA+/AChRs - sites that were NCAM+ (arrows). $c$, Twenty days after double nerve crush, laminin $\alpha 5$ labeling was maintained at sites that were VVA-positive but AChR-negative (arrows). $d$, Twenty-two days after double nerve crush (in rat muscle), laminin $\beta 2$ staining was frequently found at sites within a junction that lacked AChR staining. This lack of alignment suggests that laminin $\beta 2$ is maintained at sites that lose AChRs, because laminin $\beta 2$ normally colocalizes with AChRs (Fig. 9). Scale bars, 20 $\mu \mathrm{m}$, except where indicated. 
Similarly, phosphorylation of tyrosine residues on AChR $\beta$ subunits has been implicated in playing a role in AChR clustering by agrin (Qu et al., 1990; Wallace et al., 1991). Thus the early loss of phosphotyrosine staining is possibly related to a change in the AChRs themselves. On the other hand, even AChR $\beta$ subunits that cannot be phosphorylated are still clustered (Qu et al., 1994), and it is likely that, in addition to the AChR, other proteins that localize to clusters are also tyrosine-phosphorylated (Dai et al., 1993).

It has also been described that only the larger clusters of AChRs in myotubes studied in vitro contain utrophin in addition to rapsyn (Phillips et al., 1993). This result might mean that the formation of a large cluster of AChRs requires utrophin to aggregate smaller receptor groups. If synapse disassembly reversed the developmental process of receptor aggregation, we might expect to see disappearance of utrophin before the disappearance of large receptor clusters. We have found, however, that the disappearance of a cluster can occur even when utrophin is present. This suggests that utrophin does not protect AChR clusters from dissolution during the synapse elimination process.

We also evaluated whether there was any change in the distribution of the $\epsilon$ subunit versus the $\alpha$ subunit of the AChR. The rationale was that because the $\gamma$ subunit is present at the time synapse elimination occurs both during development and reinnervation ( $\mathrm{Gu}$ and Hall, 1988), the insertion of $\epsilon$ subunitcontaining AChRs may be restricted to sites that are preferentially maintained. However, we found no evidence of any mosaicism of endplate staining with anti- $\epsilon$ versus r-btx ( $\alpha$ subunit). In addition, the ratio of $\epsilon$-containing receptors to receptors generally was not significantly different in areas of the junction that were being maintained versus those that were eliminated. This finding is corroborated by recent work on a transgenic mouse that does not produce the $\epsilon$ subunit of the AChR. These mice, although not completely normal, do undergo developmental synapse elimination and seem to do so on a time course similar to their littermates (Missias et al., 1996).

It is notable that the molecules that were maintained for long times at sites of synapse loss had a different distribution than those that were lost. Dystrophin and syntrophin are normally found extrasynaptically and in addition are located at the depths of the postsynaptic folds (Froehner et al., 1987), rather than the crests where the molecules that were lost rapidly (AChRs, rapsyn, and utrophin) are located (Bridgman et al., 1989; Ohlendieck et al., 1991; Froehner, 1991). Because the maintenance of strong syntrophin and dystrophin staining was not permanent, it is likely that some aspects of the synaptic site disassemble at long times after axon withdrawal. One interesting possibility is that the late loss of these epitopes is related to the loss of structural features such as postsynaptic folds.

The maintenance of syntrophin labeling at sites of synapse loss, however, is complicated by the fact that there is more than one form of syntrophin (Adams et al., 1993). One of these $(\beta 2)$ has been shown to be synapse-specific, whereas the other $(\alpha 1)$ is distributed all along the muscle cell membrane (Peters et al., 1994). Because our antibody did not distinguish between these forms, it is still possible that the synapse-specific form of syntrophin ( $\beta 2)$ disappears rapidly at sites undergoing synapse elimination.

The means by which molecules disappear from postsynaptic sites undergoing synapse elimination is not known. In the case of the AChR loss the process cannot simply be explained by lack of insertion of new molecules to replace those that are normally degraded, because receptors already in the membrane disappear at a quicker rate than those at sites that are not undergoing synapse elimination (Rich and Lichtman, 1989a). For other postsynaptic molecules, it is not clear whether their disappearance from sites of synapse elimination indicates selective removal, redistribution, or a reflection of uncoupling of the normal turnover mechanisms (internalization in the absence of reinsertion). Whatever the mechanism, however, there must be a local change in the normal regulatory mechanisms of the cell to achieve a decrease in the density of molecules at one region of the postsynaptic apparatus while maintaining the normal amount throughout the rest of the junction.

A survey was also made of several extracellular constituents of the synapse that potentially could normally play a role in maintaining the overlying nerve terminal at synaptic sites, and whose disruption could be a stimulus for nerve terminal withdrawal. Laminin $\beta 2$ (Hunter et al., 1989a; Noakes et al., 1995), which is concentrated at the neuromuscular junction, has been shown to be adhesive for motor neurons in culture (Hunter et al., 1989b). This agent seems to be maintained at sites undergoing synapse elimination, however, indicating that its loss is not the cause of nerve terminal retraction. This result is consistent with the finding that synapse elimination does occur in mice lacking the laminin $\beta 2$ gene (Noakes et al., 1995). Similarly, several other potential adhesive agents in the basal lamina were also maintained at sites undergoing synapse elimination. These results should not be taken to mean that the basal lamina is unaffected by synapse elimination but, rather, suggest that any changes that potentially cause nerve terminal removal are probably quite specific.

A specific loss of agrin from the basal lamina has been shown to occur at sites that lose $\mathrm{AChR}$ staining but remain $\mathrm{AChE}$ positive at partially reinnervated frog neuromuscular junctions (Werle and Sojka, 1996). Unfortunately, we were unable to successfully stain agrin in either mouse or rat with the several antibodies we tried. Thus we were unable to ask whether agrin was specifically lost at sites undergoing competitive synapse elimination. It will also be interesting to test whether the agrin receptor complex is lost at sites of synapse elimination when such probes become available (Dechiara et al., 1996).

Recent studies have indicated that Schwann cell processes may be essential for nerve sprouting (Son and Thompson, 1995a,b). In addition, Schwann cell migration induced by application of neuregulin causes receptor loss and nerve terminal vacation from neuromuscular junctions during early postnatal life (Trachtenberg and Thompson, 1997). We thus considered the possibility that changes in Schwann cells may be involved in synaptic disassembly. We found that Schwann cell processes did vacate synaptic sites that underwent synapse elimination. In most cases, however, the changes appeared to lag slightly the loss of receptor density, suggesting that the Schwann cell processes were following, rather than initiating, the postsynaptic changes. The temporary presence of Schwann cell processes over faintly staining receptor regions is reminiscent of the transient occupation of disappearing receptor sites by nerve terminal staining. Therefore, Schwann cells could be playing a role in the removal of the nerve terminal.

\section{REFERENCES}

Adams ME, Butler MH, Dwyer TM, Peters MF, Murnane AA, Froehner SC (1993) Two forms of mouse syntrophin, a 58k dystrophinassociated protein, differ in primary structure and tissue distribution. Neuron 11:531-540.

Balice-Gordon RJ, Lichtman JW (1993) In vivo observations of presyn- 
aptic and postsynaptic changes during the transition from multiple to single innervation at developing neuromuscular junctions. J Neurosci 13:834-855.

Balice-Gordon RJ, Lichtman JW (1994) Long-term synapse loss induced by focal blockade of postsynaptic receptors. Nature 372:519-524.

Balice-Gordon RJ, Chua C, Nelson CC, Lichtman JW (1993) Gradual loss of synaptic cartels precedes axon withdrawal at developing neuromuscular junctions. Neuron 11:801-815.

Bridgman PC, Carr C, Pedersen SE, Cohen JB (1989) Visualization of the cytoplasmic surface of torpedo postsynaptic membrane by freezeetch and immunoelectron microscopy. J Cell Biol 105:1829-1846.

Brown MC, Jansen JKS, Van Essen D (1976) Polyneuronal innervation of skeletal muscle in new-born rats and its elimination during maturation. J Physiol (Lond) 261:387-422.

Carr C, Fischbach GD, Cohen JB (1989) A novel 87,000-Mr protein associated with acetylcholine receptors in Torpedo electric organ and vertebrate skeletal muscle. J Cell Biol 109:1753-1764.

Colman H, Nabekura J, Lichtman JW (1997) Alterations in synaptic strength preceding axon withdrawal. Science 275:356-361.

Covault J, Sanes JR (1985) Neural cell adhesion molecule (N-CAM) accumulates in denervated and paralyzed skeletal muscles. Proc Natl Acad Sci USA 82:4544-4548.

Covault J, Sanes JR (1986) Distribution of N-CAM in synaptic and extrasynaptic portions of developing and adult skeletal muscle. J Cell Biol 102:716-730.

Dai Z, Scotland PB, Froehner SC, Peng HB (1993) Expression of the postsynaptic $43 \mathrm{~K}$ protein in Xenopus embryonic cells and its association with phosphotyrosine. Soc Neurosci Abstr 19:1273.

Dechiara TM, Bowen DC, Valenzuela DM, Simmons M, Poueymirou WT, Thomas S, Kinetz E, Compton DL, Rojas E, Park JS, Smith C, Distefano PS, Glass DJ, Burden SJ, Yancopoulos GD (1996) The receptor tyrosine kinase $\mathrm{MuSK}$ is required for neuromuscular junction formation in vivo. Cell 85:501-512.

Froehner SC (1991) The submembrane machinery for nicotinic acetylcholine receptor clustering. J Cell Biol 114:1-7.

Froehner SC, Murnane AA, Tobler M, Peng HB, Sealock R (1987) A postsynaptic $\mathrm{M}_{\mathrm{r}} 58,000(58 \mathrm{~K})$ protein concentrated at acetylcholine receptor-rich sites in Torpedo electroplaques and skeletal muscle. J Cell Biol 104:1633-1646.

Froehner SC, Luetje CW, Scotland PB, Patrick J (1990) The postsynaptic $43 \mathrm{~K}$ protein clusters muscle nicotinic acetylcholine receptors in Xenopus oocytes. Neuron 5:403-410.

Gautam M, Noakes PG, Mudd J, Nichol M, Chu GC, Sanes JR, Merlie JP (1995) Failure of postsynaptic specialization to develop at neuromuscular junctions of rapsyn-deficient mice. Nature 377:232-236.

Gu Y, Hall ZW (1988) Immunological evidence for a change in subunits of the acetylcholine receptor in developing and denervated rat muscle. Neuron 1:117-125.

Hill RR, Robbins NJ, Fang Z-P (1991) Plasticity of presynaptic and postsynaptic elements of neuromuscular junctions repeatedly observed in living adult mice. J Neurocytol 19:85-99.

Hunter DD, Porter BE, Bulock JW, Adams SP, Merlie JP, Sanes JR (1989a) Primary sequence of a motor neuron-selective adhesive site in the synaptic basal lamina protein S-laminin. Cell 59:905-913.

Hunter DD, Shah V, Merlie JP, Sanes JR (1989b) A laminin-like adhesive protein concentrated in the synaptic cleft of the neuromuscular junction. Nature 338:229-233.

Krause M, Wernig A (1985) The distribution of acetylcholine receptors in the normal and denervated junction of the frog. $\mathrm{J}$ Neurocytol 14:765-780.

Lichtman JW (1980) On the predominantly single innervation of submandibular ganglion cells in the rat. J Physiol (Lond) 302:121-130.

Lichtman JW (1995) Synapse disassembly at the neuromuscular junction. Semin Dev Biol 6:195-206.

Lichtman JW, Magrassi L, Purves D (1987) Visualization of neuromuscular junctions over periods of several months in living mice. J Neurosci $7: 1215-1222$.

Lingle CJ, Steinbach JH (1988) Neuromuscular blocking agents. Int Anesthesiol Clin 26:288-301.
MacArdle JJ (1975) Complex end-plate potentials at the regenerating neuromuscular junction of the rat. Exp Neurol 49:629-638.

Miner JH, Lewis RM, Sanes JR (1995) Molecular cloning of a novel laminin chain, alpha 5 , and widespread expression in adult mouse tissues. J Biol Chem 270:28523-28526.

Missias AC, Chu GC, Klocke BJ, Sanes JR, Merlie JP (1996) Maturation of the acetylcholine receptor in skeletal muscle: regulation of the AChR gamma-to-epsilon switch. Dev Biol 179:223-238.

Noakes PG, Gautam M, Mudd J, Sanes JR, Merlie JP (1995) Aberrant differentiation of neuromuscular junctions in mice lacking s-laminin/ laminin beta 2. Nature 374:258-262.

Ohlendieck K, Ervasti JM, Matsumura K, Kahl SD, Leveille CJ, Campbell KP (1991) Dystrophin-related protein is localized to neuromuscular junctions of adult skeletal muscle. Neuron 7:499-508.

Peters MF, Kramarcy NR, Sealock R, Froehner SC (1994) Beta-2-syntrophin: localization at the neuromuscular junction in skeletal muscle. NeuroReport 5:1577-1580.

Phillips WD, Kopta C, Blount P, Gardner PD, Steinbach JH, Merlie JP (1991) ACh receptor-rich membrane domains organized in fibroblasts by recombinant 43-kilodalton protein. Science 251:568-570.

Phillips WD, Noakes PG, Roberds SL, Campbell KP, Merlie JP (1993) Clustering and immobilization of acetylcholine receptors by the $43 \mathrm{kDa}$ protein: a possible role for Dystrophin-related protein. J Cell Biol 123:729-740.

Qu Z, Moritz E, Huganir RL (1990) Regulation of tyrosine phosphorylation of the nicotinic acetylcholine receptor at the rat neuromuscular junction. Neuron 2:367-378.

Qu Z, Doherty C, Hoffman P, Huganir RL (1994) Regulation of tyrosine phosphorylation of the nicotinic acetylcholine receptor by the postsynaptic 43k protein. Neuroscience Abstr 20:841.

Redfern PA (1970) Neuromuscular transmission in new-born rats. J Physiol (Lond) 209:701-709.

Rich MM, Lichtman JW (1989a) In Vivo visualization of presynaptic and postsynaptic changes during synapse elimination in reinnervated mouse muscle. J Neurosci 9:1781-1805.

Rich MM, Lichtman JW (1989b) Motor nerve terminal loss from degenerating muscle fibers. Neuron 3:677-688.

Scott LJC, Bacou F, Sanes JR (1988) A synapse-specific carbohydrate at the neuromuscular junction: association with both acetylcholinesterase and a glycolipid. J Neurosci 8:932-944.

Sealock R, Butler MH, Kramarcy NR, Gao KX, Murnane AA, Douville K, Froehner SC (1991) Localization of dystrophin relative to acetylcholine receptor domains in electric tissue and adult and cultured skeletal muscle. J Cell Biol 113:1133-1144.

Son YJ, Thompson WJ (1995a) Schwann cell processes guide regeneration of peripheral axons. Neuron 14:125-132.

Son YJ, Thompson WJ (1995b) Nerve sprouting in muscle is induced and guided by processes extended by Schwann cells. Neuron 14:133-141.

Trachtenberg JT, Thompson WJ (1997) Nerve terminal withdrawal from rat neuromuscular junctions induced by neuregulin and Schwann cells. Neuroscience 17:6243-6255.

Turney SG, Culican SM, Lichtman JW (1996) A quantitative fluorescence-imaging technique for studying acetylcholine receptor turnover at neuromuscular junctions in living animals. J Neurosci Methods 64:199-208.

van Mier P, Balice-Gordon R, Lichtman J (1994) Synaptic plasticity studied in vivo using vital dyes, lasers, and computer-assisted fluorescence microscopy. Neuroprotocols 5:91-101.

Wallace BG, Qu Z, Huganir RL (1991) Agrin induces phosphorylation of the nicotinic acetylcholine receptor. Neuron 6:869-878.

Werle MJ, Sojka AM (1996) Antiagrin staining is absent at abandoned synaptic sites of frog neuromuscular junctions. J Neurobiol 30:293-302.

Wigston D (1989) Remodeling of neuromuscular junctions in adult mouse soleus. J Neurosci 9:639-647.

Woolf CJ, Reynolds ML, Chong MS, Emson P, Irwin N, Benowitz LI (1992) Denervation of the motor endplate results in the rapid expression by terminal Schwann cells of the growth-associated protein GAP43. J Neurosci 12:3999-4010. 